Revista acadêmica, avaliada por pares, independente, de acesso aberto, e multilíngue

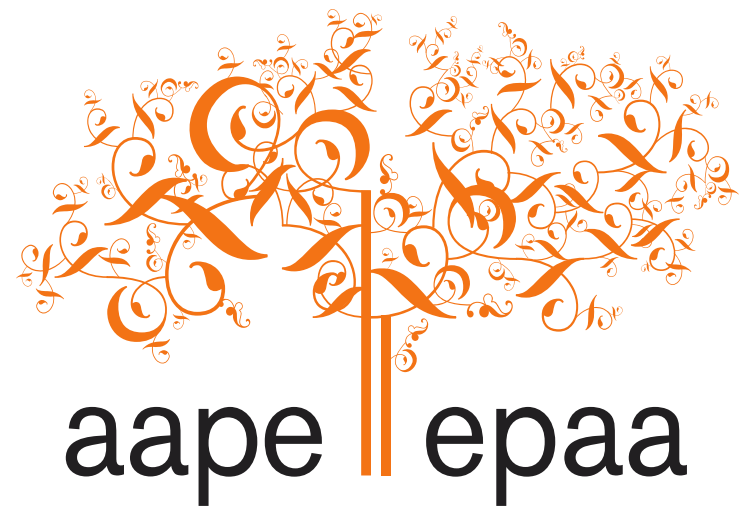

Arizona State University

\title{
Avançou? Retrocedeu? Considerações sobre os Direitos Humanos e as Ações Afirmativas para os Povos Indígenas na América Latina
}

Juliane Sachser Angnes

Universidade Estadual do Centro-Oeste do Paraná (UNICENTRO)

Programa de Pós-Graduação em Educação (PPGE UNICENTRO)

Programa de Pós-Graduação em Administração (PPGADM UNICENTRO)

\author{
\& \\ Elisa Yoshie Ichikawa \\ Universidade Estadual de Maringá (UEM) \\ Programa de Pós-Graduação em Administração (PPA UEM) \\ \& \\ Marcel Luciano Klozovski \\ Universidade Estadual do Centro-Oeste do Paraná (UNICENTRO) \\ Professor do Curso de Administração (UNICENTRO) \\ Brasil \\ \& \\ Maria de Fátima Quintal de Freitas \\ Universidade Federal do Paraná (UFPR) \\ Programa de Pós-Graduação em Educação (UFPR) \\ Brasil
}

Citação: Angnes, J. S., Ichikawa, E. Y., Klozovski, M. L. \& Freitas, M. F de Q.(2020). Avançou? Retrocedeu? Considerações sobre os direitos humanos e as ações afirmativas para os povos 
Indígenas na América Latina. Arquivos Analíticos de Políticas Educativas, 28(160). https://doi.org/10.14507/epaa.28.4768 Este artigo faz parte do dossiê especial, Educação e Povos Indígenas - Identidades em Construção e Reconstrução, editado por Juliane Sachser Angnes e Kaizo Iwakami Beltrão.

Resumo: Este ensaio teórico se propôs a compreender como se configura a concepção contemporânea de Direitos Humanos, e a partir disso, articular as Ações Afirmativas para os Povos Indígenas inseridas nesta concepção. Ou seja, se propõe em refletir de que forma ocorreu este processo na América Latina, ou seja, se estas ações propostas na América Latina para os Povos Indígenas adotam uma perspectiva constituída no "sujeito de direito" sendo visto em sua particularidade e peculiaridade, apresentando se houve avanços ou retrocessos. Os resultados apontaram que, especificamente, que a partir das concepções apresentadas na OIT houve uma quebra do paradigma integracionista mostrando um verdadeiro avanço frente às concepções e às formas como as sociedades indígenas são compreendidas, pelo menos na legislação aplicada na América Latina. Todavia, há muito ainda que se refletir e lutar.

Palavras-chave: direitos humanos; ações afirmativas; América Latina; avanços; retrocessos

Did you advance? Did you back down? Human rights and affirmative actions for Indigenous peoples in Latin America

Abstract: This theoretical essay proposes to understand how the contemporary conception of Human Rights is configured, and from that, to articulate the affirmative actions for Indigenous peoples inserted in this conception. In other words, it reflects on how this process took place in Latin America, that is, whether these actions proposed in Latin America for Indigenous peoples adopt a perspective constituted by the "subject of law" being seen in its particularity and peculiarity, and whether there have been advances or setbacks. The results showed that, specifically, from the conceptions presented at the International Labor Organization (OIT) there was a break in the integrationist paradigm, showing a real advance in the expressions of these conceptions and the ways in which indigenous societies are understood, at least in the applied legislation in Latin America. However, there is still much to reflect on and fight for.

Keywords: human rights; affirmative actions; Latin America; advances; setbacks

\section{¿Avanzaste? ¿Retrocediste? Derechos humanos y acciones afirmativas para los pueblos Indígenas en America Latina}

Resumen: Este ensayo teórico propuso comprender cómo se configura la concepción contemporánea de los derechos humanos y, a partir de eso, articular las acciones afirmativas para los pueblos indígenas insertadas en esta concepción. En otras palabras, propone reflexionar sobre cómo se llevó a cabo este proceso en America Latina, es decir, si estas acciones propuestas en Amrica Latina para los pueblos indígenas adoptan una perspectiva constituida por el "sujeto de derecho" visto en su particularidad y peculiaridad, presentando si ha habido avances o retrocesos. Los resultados mostraron que, específicamente, a partir de las concepciones presentadas en la Organización Internacional del Trabajo (OIT), hubo una ruptura en el paradigma integracionista que mostró un avance real frente a las concepciones y las formas en que se entienden las sociedades indígenas, al menos en la legislación aplicada en America Latina. Sin embargo, todavía hay mucho por lo que reflexionar y luchar.

Palabras-clave: derechos humanos; acciones afirmativas; America Latina; avances; contratiempos 


\section{Introdução}

[...] temos o direito a ser iguais quando a nossa diferença nos inferioriza; e temos o direito a ser diferentes quando a nossa igualdade nos descaracteriza. Daí a necessidade de uma igualdade que reconheça as diferenças e de uma diferença que não produza, alimente ou reproduza as desigualdades”. (Santos, 2003)

Como se configura a concepção contemporânea de Direitos Humanos? É possível articularmos as Ações Afirmativas para os Povos Indígenas inseridas nesta concepção? De que forma ocorreu este processo na América Latina? A partir destas questões direcionadoras - por que não dizer perturbadoras - é que direcionamos a reflexão proposta neste texto. Ou seja, será mesmo que as Ações Afirmativas propostas na América Latina para os Povos Indígenas adotam uma perspectiva constituída no "sujeito de direito" sendo visto em sua particularidade e peculiaridade? Será que tivemos avanços neste sentido? Ou retrocessos? Será que não escondemos as Ações Afirmativas atrás do "mito da democracia racial"?

Para tanto, dividimos esta reflexão em três direcionamentos. Num primeiro momento realizamos uma explanação sobre a concepção contemporânea de Direitos Humanos e como podemos conceber as Ações Afirmativas nesta perspectiva. Ou seja, ao trazer a tona à discussão sobre a necessidade de instituir, além de medidas punitivas a toda e qualquer discriminação racial, incentivar esta proibição da discriminação com políticas compensatórias que acelerassem a igualdade como processo.

Num segundo momento pactuamos uma breve contextualização das Ações Afirmativas na América Latina. Neste processo, trouxemos uma discussão referente ao processo de luta dos movimentos sociais de negros, povos indígenas, mulheres, deficientes entre outros por ações afirmativas problematizando que estes enfrentaram e ainda enfrentam enormes dificuldades para se efetivar, enquanto política compensatória, fundamentada no princípio de igualdade que sustenta o tratamento igual aos desiguais, usualmente aplicada de acordo com critérios socioeconômicos; mais especificamente, pode ser política compensatória voltada para determinado grupo, definido a partir de características adstritas como "raça", "gênero" ou "etnia".

Por sua vez, num terceiro momento historicizamos os rumos assumidos na luta dos direitos dos povos indígenas da América Latina e as relações assumidas por estes no que se refere às Ações Afirmativas para a busca de tratamentos mais humanos contra o processo de integração, mas sim, de convívio com as diferenças. Em outras palavras, a perspectiva que demanda igualdade material e social nos Direitos Humanos é plenamente justificada por meio das Ações Afirmativas aos povos indígenas por seu histórico de genocídio, etnocídio, políticas de exclusão, assimilação e discriminação. Um histórico de atividades, sobretudo estatais, que explicam porque a mera igualdade perante a lei não é suficiente. Ou seja, o paradigma individualista liberal do direito ocidental só gerou exclusão aos povos indígenas. A fórmula individualista de consagração de direitos ao cidadão uno, nunca incluiu os povos indígenas. Muito pelo contrário, negou-lhes a existência enquanto "coletividade", para integrá-los na fórmula totalizante da "individualidade".

\section{Direitos Humanos e as Ações Afirmativas: Igualdade de Direitos e Inclusão Social}

Conforme destaca Piovesan (2005, p.44) "como reivindicações morais os direitos humanos nascem quando devem e podem nascer". Neste prisma a autora destaca que compactua com Bobbio (1988) e com Arendt (1988) que os direitos humanos além da não nascerem todos de uma vez, são construídos e reconstruídos em um espaço simbólico de luta e ação social. Em 
outras palavras, a autora citada salienta que para ela os direitos humanos compõem uma racionalidade de resistência, na medida em que "traduzem processos que abrem e consolidam espaços de luta pela dignidade humana" (Flores, mimeo) que somados podem "evitar sofrimentos, em face da persistente brutalidade humana".

Desta forma, foi a partir desta perspectiva historicamente construída que a Declaração Universal promulgada em 1948 trouxe inovações ao introduzir a denominada concepção contemporânea de direitos humanos, marcada pela universalidade e indivisibilidade desses direitos. Segundo a autora,

O processo de universalização dos direitos humanos permitiu a formação de um sistema internacional de proteção desses direitos. Esse sistema é integrado por tratados internacionais de proteção que refletem, sobretudo, a consciência ética contemporânea compartilhada pelos estados, na medida em que invocam o consenso internacional acerca de temas centrais aos direitos humanos, na busca da salvaguarda de parâmetros protetivos mínimos - do "mínimo ético irredutível”. (Piovesan, 2005, p. 45)

A partir da citação da autora, entendemos que a Declaração Universal dos Direitos Humanos, sob esta concepção moderna fomentou e incentivou os pactos internacionais de proteção de direitos humanos a interagirem em benefício dos sujeitos protegidos. Lógico, vale destacar que numa primeira fase, incentivados pela tônica de proteção geral, que expressava o temor da diferença (que no nazismo havia sido orientada para o extermínio) os direitos humanos se focavam na igualdade geral e formal (Piovesan, 2005).

Contudo, numa segunda fase, superada esta igualdade geral e formal acentuada pela luta contra a intolerância (etnia, raça, religião entre outras) as pessoas passam a ser vistas pelos direitos humanos não mais de forma genérica, geral e abstrata. Tais constructos passam a ser insuficientes para tratar os indivíduos. Portanto, é nesta fase que surge o "sujeito de direito" sendo visto em sua particularidade e peculiaridade. Piovesan (2005) confirma este aspecto ao trazer que,

Nessa ótica determinados sujeitos de direitos, ou determinadas violações de direitos, exigem uma resposta específica e diferenciada. Vale dizer, na esfera internacional, se uma primeira vertente de instrumentos internacionais nasce com a vocação de proporcionar uma proteção geral, genérica e abstrata, refletindo o próprio temor da diferença (que na era Hitler foi justificativa para o extermínio e a destruição), percebe-se, posteriormente, a necessidade de conferir, a determinados grupos, uma proteção especial e particularizada. (Piovesan, 2005, p. 47)

A partir do expõe a autora torna-se explícito que a "diferença" sob o enfoque moderno dos direitos humanos passa a não ser mais utilizada como aniquilação de direitos. Muito pelo contrário, esta "diferença" surge como direcionamento para a promoção de direitos. Dessa forma, fundamentado nesta perspectiva, desde a década de 1970, o debate sobre os direitos das minorias vem se constituindo na América Latina, com destaque para os processos que buscam garantir o acesso ao conjunto de políticas públicas que historicamente foram negligenciadas a todo um grupo de cidadãos, tendo como exemplo, os remanescentes de áreas quilombolas, os indígenas, os deficientes, as mulheres, crianças entre outros.

Assim, temos um cenário na América Latina em franco florescimento a partir da década de 1970 no qual os "Direitos Humanos" contemplam como um dos fios condutores o respeito à diferença e à diversidade, para estes grupos que passam a ser vistos nas especificidades e peculiaridades de sua condição social o que lhes assegura um tratamento especial. Consoante ao direito à igualdade, vemos surgir, também, como direito fundamental, o direito à diferença. Seguindo essa linha teórica, Santos (2003, p. 34) afirma que surge daí a necessidade de uma 
igualdade que reconheça as diferenças e de uma diferença que não produza, alimente ou reproduza as desigualdades.

Mas como o florescimento desta perspectiva nos Direitos Humanos chega até a América Latina? Fomentada por pesquisadores que se pautaram na Convenção sobre a Eliminação de Todas as Formas de Discriminação Racial elaborada pelas Nações Unidades em 1965 e ratificada por 170 países em 1968. Ou seja, ao trazer a tona à discussão sobre o conteúdo desta convenção, os pesquisadores "abriram o debate" sobre a necessidade de instituir, além de medidas punitivas a toda e qualquer discriminação racial, incentivar esta proibição da discriminação com políticas compensatórias que acelerassem a igualdade como processo.

Conforme Santos (2003), para assegurar a igualdade não bastava apenas proibir a discriminação mediante legislação repressiva. Seriam essenciais as estratégias promocionais capazes de estimular a inserção e inclusão de grupos socialmente vulneráveis nos espaços sociais. Com efeito, a igualdade e a discriminação pairam sob o binômio inclusão-exclusão. "Enquanto a igualdade pressupõe formas de inclusão social, a discriminação implica a violenta exclusão e a intolerância à diferença e à diversidade" (Piovesan, 2005, p. 56). Nesse sentido, como poderoso instrumento de inclusão social, situam-se as ações afirmativas.

$\mathrm{Na}$ América Latina, a conceituação referente ao termo "ação afirmativa" ainda gera controvérsias entre pesquisadores, professores, juristas, mídia e na maioria da população. Grande parte das discussões se desenvolve principalmente em dois posicionamentos: a) "políticas de cotas" e b) "cópia da política implementada nos Estados Unidos da América (EUA)".

Em relação ao primeiro posicionamento que associa o conceito de "ação afirmativa" a "política de cotas" convém destacar a incompreensão quanto à dimensão e à abrangência dessas ações. Ou seja, não se pode reduzir ou confundir ações afirmativas a regimes ou sistemas de cotas. Ação afirmativa não é sinônima de cotas! As cotas constituem apenas um instrumento de aplicação da política de ação afirmativa.

Para Silva Freitas (2010, p. 108), “cotas numéricas são comumente confundidas com ação afirmativa, o que é um equívoco". De acordo com esta autora, as cotas são um aspecto ou possibilidade da ação afirmativa que, em muitos casos, tem um efeito pedagógico importante, posto que forcem o reconhecimento do problema da desigualdade e a implementação de uma ação concreta que garanta os direitos (ao trabalho, à educação, à promoção profissional) às pessoas em situação de inferioridade social.

Nessa situação tem-se como referência prática no Brasil a experiência das cotas partidárias para mulheres, iniciada pelo Partido dos Trabalhadores (PT), em $1991^{1}$, referentes aos cargos de direção do partido, e expandida para todos os partidos, com relação ao número de candidatos a serem incluídos nas listas partidárias, em nível nacional, a partir de 1995; a experiência de cotas nas direções partidárias da Central Única dos Trabalhadores (CUT), em 1992; e as reivindicações do Movimento Negro no país solicitando criação de cotas em universidades públicas federais e estaduais.

Assim, podemos observar nos exemplos anteriores que o sistema de cotas faz parte de um conjunto de ações afirmativas para minimizar ou eliminar uma situação de vulnerabilidade decorrente de um quadro de desigualdade ou discriminação com vistas a corrigir ou compensar tal situação de origem socioeconômica discriminatória. Por sua vez, no que tange ao segundo posicionamento que referenda o conceito de "ação afirmativa" a "cópia da política implementada nos Estados Unidos da América (EUA)" tem-se como base fundamental os ideais democráticos norte-americanos.

\footnotetext{
${ }^{1}$ A cota mínima de 30\% de mulheres nas direções partidárias foi aprovada no Primeiro Congresso do Partido dos Trabalhadores (PT), realizado entre 27 de novembro e 01 de dezembro de 1991. As direções estaduais e municipais foram renovadas pela primeira vez com o dispositivo das cotas em 1992 e a direção nacional em 1993 (Godinho, 1996).
} 
Bezerra (2008, p. 35) destaca que as ações afirmativas passaram a ter um maior destaque a partir da sua adoção nos Estados Unidos da América (EUA) durante a década de 1960. Porém, salienta que sua origem foi na Índia, em 1919, quando o jurista, economista e historiador Bhimrao Ramji Ambedkar tentou convencer as autoridades de implementar o que ele chamou de "representação diferenciada" que propunha que a Índia adotasse medidas para quebrar o sistema de $\operatorname{castas}^{2}$ por meio de políticas públicas diferenciadas para que houvesse igualdade entre todos os segmentos sociais.

Todavia, Oliven (2009) aponta que o termo "ação afirmativa" foi primeiramente empregado em 1961, durante o governo Kennedy, nos Estados Unidos da América (EUA), que constituiu um comitê para estudar a questão das oportunidades iguais no mercado de trabalho. Inicialmente, as primeiras políticas de ação afirmativa implementadas nesse país foram dirigidas à população negra, posteriormente, foram estendidas às mulheres e depois a algumas minorias étnicas e a estrangeiros. À época, o país se viu diante de reivindicações democráticas internas, expressas principalmente no movimento pelos direitos civis, defendendo a ampliação da cidadania e a igualdade de oportunidades para todos.

Foi neste contexto que surgiram as ações afirmativas neste país, fazendo com que o Estado, além de garantir leis antissegregacionistas, viesse a assumir uma postura ativa em benefício das populações excluídas. Dessa forma, nos EUA, tais ações desenvolveram-se em diferentes áreas como o mercado de trabalho e o sistema educacional, principalmente em nível superior.

De acordo com Bergmann (1996) as ações afirmativas nos Estados Unidos da América (EUA) assumiram formas como programas de ações e políticas, governamentais ou privadas, leis ou orientação de decisões jurídicas, e levaram à constituição de agências de fomento e regulação, como a Comissão para Igualdade de Oportunidades no Emprego, tendo a Lei de Direitos Civis (Civil Rights Act), aprovada em 1964, como seu principal fundamento legal.

Já Moehlecke (2000, p. 180) afirma que "os Estados Unidos foram a principal referência para a discussão sobre políticas públicas voltadas para a questão racial e social na América Latina, apesar das experiências envolvendo ações afirmativas não estarem restritas a esse país". Porém, a mesma autora salienta que utilizar o exemplo de ações afirmativas aplicadas pelos EUA para fundamentar as relações e políticas raciais e sociais, expõe a América Latina a situações contraditórias e equivocadas.

Entende-se com isso que ao mesmo tempo em que as ações, conquistas e resultados alcançados nos EUA foram importante exemplo de um Movimento Negro organizado e forte e do êxito no tratamento da questão da política racial, as possibilidades de experiências semelhantes ocorrerem na América Latina foram/são muito contestadas, porque o tipo de racismo existente naquele país, com sua história de segregação e discriminação ${ }^{3}$, foi/é diferente do racismo latino-americano.

Para Oliven o termo "ação afirmativa" refere-se a "um conjunto de políticas públicas para proteger minorias e grupos que, em uma determinada sociedade, tenham sido discriminados no passado" (2010, p. 76). A ação afirmativa visa remover barreiras, formais e informais, que

\footnotetext{
${ }^{2}$ Wedderburn define o sistema de castas indiano como "uma estrutura milenar de opressão, embutida de conceitos religiosos do hinduísmo. Esse sistema se articula em torno de conceitos de superioridade e inferioridade, de pureza e de impureza, que não envolvem somente critérios religiosos, mas sócio-raciais, apresentando as castas superiores como uma origem ariana" (Wedderburn, 2005, p. 314).

3 "A discriminação é direta quando as regras e práticas explicitamente excluem ou dão preferência a certas pessoas com base apenas no seu pertencimento a um grupo determinado. Por outro lado, a discriminação indireta refere-se a normas, procedimentos e práticas que parecem neutras, mas cuja aplicação afeta de maneira desproporcional membros de um determinado grupo. Enquanto a discriminação direta e aberta é fácil de ser detectada, pode ser difícil provar a existência da discriminação indireta, especialmente quando ela resulta em desproporção, mas não na exclusão total de membros de certos grupos na sociedade"
} (Munanga, 1996, p. 75). 
impeçam o acesso de certos grupos ao mercado de trabalho, universidades, posições de liderança. Ou seja, em termos práticos, as ações afirmativas incentivam as organizações a agir positivamente, a fim de favorecer pessoas de segmentos sociais discriminados a terem oportunidade de ascender a postos de comando.

Por sua vez Guimarães propõe que "ação afirmativa" significa "promover privilégios de acesso a meios fundamentais - educação e emprego, principalmente - a minorias étnicas, raciais ou sexuais que, de outro modo, estariam deles excluídas, total ou parcialmente" (1997, p. 233). Ou seja, para o autor essas ações constituem medidas especiais e temporárias que, buscando remediar um passado discriminatório, objetivam acelerar o processo de igualdade, com o alcance da igualdade substantiva por parte de grupos vulneráveis, como as minorias étnicas e raciais, as mulheres, dentre outros grupos.

Na perspectiva apresentada por Guimarães (1997) convicção que se estabelece na filosofia do direito (principalmente os Direitos Humanos) é de que tratar pessoas, de fato, desiguais como iguais somente amplia a desigualdade inicial entre elas. "Justifica-se assim a desigualdade de tratamento no acesso aos bens e aos meios apenas como forma de restituir tal igualdade, devendo, por isso, tal ação ter caráter temporário, dentro de um âmbito e escopo restrito" (Guimarães, 1997, p. 233).

Para Santos et al. (1999), há uma associação entre "ação afirmativa" e as políticas compensatórias, especificamente as "destinadas a equipar pessoas ou grupos historicamente prejudicados em virtude de discriminação sofrida". (1999, p. 212) Acrescenta ainda que "o próprio conceito de ação afirmativa exige a certeza de que tenha ocorrido discriminação passada e presente, para que sejam elaborados caminhos que levem a uma compensação efetiva da perda ocorrida." (Santos et al, 1999, p. 213) Com esta afirmação, o autor introduz a ideia de ação afirmativa como política compensatória, vinculada a indivíduos ou grupos definidos pela discriminação por eles sofrida.

Por sua vez Santos (2005) afirma que "a ação afirmativa engloba, além da simples extinção da prática discriminatória, qualquer medida adotada para corrigir e/ou compensar por atos discriminatórios passados ou presentes, bem como para prevenir novas ocorrências". Segundo Contins \& Sant'Ana (1996) a "ação afirmativa" teria,

Como função específica a promoção de oportunidades iguais para pessoas vitimadas por discriminação. Seu objetivo é, portanto, o de fazer com que os beneficiados possam vir a competir efetivamente por serviços educacionais e por posições no mercado de trabalho. (Contins \& Sant'ana, 1996, p. 210)

Com base na citação proposta, Jacooud \& Theodoro (2005) acrescentam as ações afirmativas podem enfocar a questão racial e também atingir grupos discriminados.

Observa-se, de um lado, que as ações afirmativas não se reduzem a política de cotas e, de outro, que elas não esgotam o conjunto de políticas públicas necessárias à promoção da igualdade racial. De fato, as ações afirmativas são políticas amplas que se inserem no campo da promoção da igualdade de oportunidades, facilitando o acesso dos grupos discriminados a certos espaços da vida social. (Jacooud \& Theodoro, 2005, p. 113)

A partir das definições apresentadas, assumimos neste texto o posicionamento que a "ação afirmativa" seja uma política compensatória, fundamentada no princípio de igualdade que sustenta o tratamento igual aos desiguais, usualmente aplicada de acordo com critérios socioeconômicos; mais especificamente, pode ser política compensatória voltada para determinado grupo, definido a partir de características adscritas como "raça", "gênero" ou "etnia (Campos \& Feres Júnior, 2014, p. 111). Também, partimos do pressuposto que a ação afirmativa seja uma política de diversidade, que reivindica não uma igualdade de bens materiais, mas culturais, educacionais, com valores justos e éticos numa exigência de reconhecimento de identidades coletivas tão discutidas no âmbito dos Direitos Humanos. 
Convém destacar que independentemente da terminologia, todas estas medidas visam acelerar o ritmo de participação dos membros de grupos sub-representados, no acesso ao emprego, educação, treinamento e promoção. Em outras palavras, compreendemos que tais medidas compensatórias buscam superar obstáculos institucionais e sociais que impeçam membros destes grupos de se beneficiarem da oportunidade de emprego em igualdade de condições com outros membros da sociedade.

\section{Ações Afirmativas na América Latina: Breve Contextualização}

$\mathrm{Na}$ América Latina as primeiras ações afirmativas incorporadas dizem respeito à reserva de vagas para as mulheres na esfera política. De acordo com Bezerra (2008, p. 36) “o primeiro país deste continente a implantar ações afirmativas foi à Argentina, com destinação de $30 \%$ das vagas de partidos políticos sendo destinadas às mulheres". Posteriormente, outros países do continente (México, Chile, Brasil) também adotaram ações afirmativas voltadas para a questão de gênero em 1995.

Entretanto, Wedderburn apresenta que "houve resistência desses mesmos países da América do Sul em adotar ações afirmativas para outros segmentos como, por exemplo, negros e índios" (2005, p. 72). Estes segmentos, por sua vez, lançaram propostas mediante a luta e mobilização social, para que houvesse ações afirmativas que visassem combater a discriminação e a desigualdade impostas por séculos de colonização e escravidão.

Assim, o processo de luta dos movimentos sociais de negros e índios por ações afirmativas enfrentou e ainda enfrenta enormes dificuldades para se efetivar, isso porque na América Latina impera o modelo de sociedade baseado estratificação social e econômica, no patriarcalismo, no sexismo, no racismo e na discriminação etnicorracial. Nesse sentido, Caleffi acrescenta que,

$\mathrm{Na}$ América Latina, nota-se que a uma parte da sociedade se concebe e se aceita como 'países multiculturais' há pouco tempo, pois a noção que persistiu no século $\mathrm{XX}$, até a década de 60 , entendia a presença de diferentes culturas, dentro de um único Estado-Nação como algo transitório, a ser superado. (Caleffi, 2004, p. 2)

Complementando a afirmação Amparo Alves (2009) ressalta que na América Latina, assim como em outros países em desenvolvimento, impera o paradigma capitalista/neoliberal ${ }^{4}$ que foi estruturado em torno de um projeto de investimento econômico, político, cultural, social e educacional no modelo ocidentalizado ou (neo)colonizador,

a) contínuo, pois a riqueza e o poder estão concentrados nas mãos da elite hegemônica; b) circular, à medida que tudo gira em torno dos interesses desse grupo e de seus descendentes em manter a estrutura global de opressão; c) constante e cumulativo, visto que, com a lógica da exploração e da espoliação, essa elite e seus representantes investem em diferentes tecnologias de poder para manter suas riquezas. (Amparo Alves, 2009, p. 38)

Entendemos tratar-se de um modelo branco elitizado de dominação, apropriação e manutenção de poder, riquezas e várias formas de conhecimento sobre os não-brancos. Por isso, o processo de luta dos movimentos sociais de negros e índios por ações afirmativas se depara com

\footnotetext{
${ }^{4}$ De modo geral, esse paradigma refere-se a um conjunto de medidas denominado Consenso de Washington, formulado e implementado nos países de "terceiro mundo" por instituições internacionais, tais como FMI e Banco Mundial que, a partir da década de 1970, criaram programas de ajustes estruturais, recomendando a privatização, a desregulamentação dos mercados e o corte de gastos sociais, provocando um constante (des)investimento do Estado na formulação de políticas públicas nesses países, chamados "subdesenvolvidos" (Amparo Alves, 2009; Harvey, 2005; Klein, 2007 ).
} 
resistência e críticas desse modelo branco elitizado de dominação, que argumenta a existência de uma democracia racial ou "mestiçagem" e a impossibilidade de se formular políticas afirmativas para grupos raciais em países compostos por populações "multicromáticas", além de afirmar que ao se adotar ações afirmativas no continente latino-americano se faria uma imitação inadequada das políticas implantadas nos EUA.

Ao analisarmos as afirmações propostas por Sousa (2009) e Amparo Alves (2009) percebemos que estas apresentam distintas posições ideológicas. Há um "embate" entre a ênfase da estratificação social versus à dominação "branca" no continente latino-americano.

Para reforçar a posição de estratificação social o Banco Mundial (BM) utiliza o Chile como exemplo na questão educacional em nível superior. Siqueira (2004) traz que o BM considera o Chile como um país que na década de 1970, aplicou um projeto piloto para a América Latina e para o mundo na implementação de políticas neoliberais, privatistas e de ajustes estruturais. Políticas estas que foram massacrantes para o Chile e para as populações da América Latina. Ou seja, a partir de 1970, o BM criou programas de ajustes estruturais, recomendando a privatização, a desregulamentação dos mercados e o corte de gastos sociais, provocando um constante (des)investimento do Estado na formulação de políticas públicas nos países, chamados "subdesenvolvidos", aprofundando a pauperização e marginalização de grandes setores da população da América Latina.

Neste sentido, consideramos que a estratificação social imposta pelo BM às populações latino-americanas foi uma tragédia, haja vista que provocou uma série de transformações nas estruturas produtivas e tecnológicas. Estas mudanças afetaram, sobretudo, a legislação e as relações de trabalho na região, causando um grande índice de desemprego, levando um considerável número de trabalhadores em busca de empregos informais. Por exemplo, no setor informal, o índice de trabalhadores tornou-se desolador: na Bolívia, 75,2\% da população (2002), no Brasil, 54,2\% (2004), na Venezuela, 51,1\% (2004), na Guatemala, 69\% (2004), no México, 50,1\% (2004), na Argentina, 42,5\% (2003) e no Chile, 38\% (2003) da população (Klein, 2007).

Os índices apresentados confirmam o domínio imposto às populações latino-americanas incentivado pelo BM nestes países. Ou seja, as reformas estruturais impostas pelo BM na década de 1970, causaram danos visíveis ao tecido social nos países que os ajustes operaram. $\mathrm{Na}$ educação superior do Chile, houve a questão dos empréstimos aos estudantes pobres e desfavorecidos que ganhou destaque na mídia.

Segundo Siqueira (2004, p. 119) "o foco principal dessa reforma parece ter sido o direcionamento dos recursos públicos das universidades tradicionais para o setor privado". Com esse posicionamento justificou-se o corte de recursos orçamentários na educação pública, já que esses estudantes tiverem linhas de crédito para financiar sua formação universitária, sendo responsáveis por sua qualificação e ascensão socioeconômica. Considera-se este posicionamento adotado na época pelo estado chileno foi abusivo, pois nada justifica o corte de investimentos em educação pública para transferência de recursos na esfera educacional privada.

Entretanto Wedderburn (2005) salienta que somente argumentos como os de estratificação social servem para dificultar o processo de reconhecimento da discriminação na América Latina e as desvantagens que os negros e os índios herdaram após um longo período de escravidão e colonização. Concordando, Munanga (2004, p. 124) afirma que de fato, o projeto de branqueamento "sustentado e experimentado pela elite ideológica e estrategista como solução às mazelas raciais" ainda permanece na configuração político-econômica e educacional na América Latina assim como a insistência no discurso da existência de uma discriminação social no lugar de uma discriminação etnicorracial na região.

Partimos do pressuposto que na América Latina haja tanto a questão racial quanto a questão da estratificação social sendo tratadas e discutidas. Em resposta a todo esse processo observamos, sobretudo na América Latina, movimentos que atuam de forma significativa na luta contra o projeto neoliberal e ao próprio modelo de globalização imposto pelo capital. 
Neste cenário político emergem "novos" sujeitos sociais, sendo o movimento indígena um dos principais, tendo como resultado de suas práticas a forte influência na decisão de campanhas eleitorais presidenciais, como, por exemplo, o caso de Evo Morales na Bolívia em 2006, e a criação de organizações sociais representativas, por exemplo, a Coordenadora Andina de Organizações Indígenas, a Confederação Nacional de Comunidades Afetadas pela Mineração do Peru e a Coordenadora Nacional de Ayllus e Marqas. No entanto, destacamos como principal exemplo da organização indígena e do seu poder de mobilização, o levante organizado pelo Exército de Libertação Nacional (EZLN) no estado mexicano de Chiapas. (Amparo Alves, 2009)

Ramos apresenta em seus estudos que na América Latina, os movimentos e partidos de esquerda sempre falaram em aliança operária e camponesa, sem levar em consideração o elemento indígena no processo de renovação social. No entanto, têm-se algumas exceções no que tange a estudos sobre o papel dos indígenas nos movimentos sociais, como é o caso das obras de José Carlos Mariátegui ${ }^{5}$, que valorizam o componente indígena no processo de renovação social da nação peruana, procurando com isso potencializar sua ação política autônoma (Ramos, 2003).

Desta forma, consideramos que as lições dos movimentos indígenas no México, no Equador, na Bolívia e em outras partes, são provas de que é possível colocar o poder em crise com uma mobilização pacífica, civil, massiva e que resulta a partir de "baixo". Falando sobre a realidade na Bolívia, García Linera ${ }^{6}$ citado por Ramos (2003, p. 39) destaca que as elites custam a compreender a emergência desse novo ator social. Segundo ele, a elite está "muito acostumada a mandar sozinha, por tradição, por herança, por hábito, por costume e por formação. Os indígenas sempre eram os que serviam à mesa, cozinhavam, cuidavam das crianças, eram pedreiros". (Ramos, 2003, p. 39).

A partir das organizações e atuações do movimento indígena, reconhecemos que existe, na atualidade, um novo núcleo articulador do poder político na América Latina. Esse novo núcleo articulador do poder, como afirma Linera, manifesta-se, por exemplo, no Paraguai em 2008, onde, pela primeira vez, os indígenas do país exerceram um papel importante na articulação de uma candidatura à presidência do país .

Por meio do exposto, entendermos então que o movimento indígena defende que as ações afirmativas surgem como legítimas no continente latino-americano, mas devem levar em consideração as particularidades históricas desse território e de suas populações. Para Almdeia:

Ao longo desses séculos de resistência que a população indígena não tem tido o direito de contar e escrever sua própria história e permanece desumanizada, submetida à subalternidade, sem acesso a direitos fundamentais, à educação pública democrática, e a políticas públicas de ações afirmativas e reparatórias, Integrantes dos movimentos indígenas tem salientado a importância de que o branco ocidental hegemônico deve renunciar intencionalmente aos privilégios estabelecidos pelo branqueamento em favor da realização da plena humanidade de todos. Esse é um dos requisitos prévios fundamentais para uma globalização humanitária (Almeida, 2009, p. 40).

\footnotetext{
${ }^{5}$ Mariátegui (1894-1930) foi o primeiro marxista da América Latina a abordar os problemas agrários e suas relações com a problemática indigenista, tentando aplicar uma outra forma de marxismo conforme a realidade latino-americana. (Fajardo, 2010).

${ }^{6}$ Vice-presidente boliviano; compôs chapa com o atual presidente Evo Morales nas eleições presidenciais de 2006.

${ }^{7}$ O ex-bispo Fernando Lugo candidato do partido Aliança Patriótica para a Mudança (APC); foi o candidato apoiado pelo movimento popular Tekojoja, o qual conta com forte participação indígena nas eleições presidenciais do Paraguai em 2008 (Beltrão, 2008).
} 
Em um estudo realizado por Hooker apud UNESCO (2009) ${ }^{8}$ referente a situação da América Latina foi apresentado o grau de desigualdade e de discriminação contra populações indígenas na região. A pesquisa apontou que houve algumas reformas em países como Peru, México, Colômbia, Venezuela, e que os povos indígenas conseguiram alguns poucos avanços em relação aos afrodescendentes na conquista dos direitos coletivos. De acordo com Hooker "somente no Brasil e na Colômbia a situação se inverte onde há meios legais para tratar do assunto relativo à legislação dos direitos civis e educacionais dos afrodescendentes" (Hooker apud Unesco, 2015).

Isso não quer dizer que os povos indígenas já tenham todos os seus direitos contemplados politicamente nos países da América Latina, ou que não sofram as consequências do racismo e da discriminação social e étnico-racial. Como herança colonial, os povos originários sofreram e sofrem problemas afins vinculados à desapropriação territorial, à subordinação política, à debilitação cultural e à discriminação.

Salienta-se que após acontecimento colonial seguiram-se as políticas de extermínio e assimilação do século XIX, o integracionismo forçado de meados do século XX e, finalmente, as políticas de ajuste estrutural de fins do século XX e início do século XXI, as quais tem significado novas formas de exclusão para os povos indígenas e, inclusive, tem posto em questão sua própria existência enquanto povos.

O impacto dessas políticas de extermínio, assimilação e ajustes estruturais foram perversas para as populações indígenas, e as colocou entre os excluídos em termos de taxas de pobreza, exploração do trabalho, falta de acesso aos recursos e serviços básicos, analfabetismo e a situação agrava-se no caso das mulheres e crianças, pois a variável de exclusão étnica une-se ao gênero e idade.

\section{Avanços? Retrocessos? Ações Afirmativas para os Povos Indígenas na América Latina}

Como dissemos anteriormente, o final da década de 1960 e o início da década de 1970 foram fundamentais para a compreensão dos rumos assumidos na luta dos direitos dos povos indígenas na América Latina. Anterior a esta data, ao longo do século XX, havia basicamente duas posições dos não-índios em relação aos índios. A primeira, que desconhecia fundamentalmente o direito dessas populações, inclusive da própria vida, considerando-as um entrave ao progresso dos estados nacionais, ignorando extermínios praticados pelos integrantes das frentes de expansão, responsáveis por levar a modernidade às áreas mais remotas dos países latino-americanos.

E, a segunda posição dava continuidade à luta iniciada por frei Bartolomeu de Las Casas que pretendia, com uma atitude paternalista, defender os índios dos abusos e maus-tratos a eles impetrados pela dinâmica da sociedade colonizadora. Esta posição foi seguida por muitas pessoas, inclusive por intelectuais, que reforçavam as lutas indígenas com tratamentos mais humanos (Caleffi, 2004). Compreendemos que tanto a primeira, quanto a segunda posição, apresentavam como paradigma o extermínio dos povos indígenas, não por meio de atitudes violentas, mas aceitando como natural e inevitável o seu desaparecimento mediante sua integração à sociedade colonizadora.

Complementando Fajardo (2010) salienta que houve dois instrumentos internacionais que marcaram o horizonte das políticas afirmativas para os povos indígenas nestes dois posicionamentos. São eles: “a) Convenção sobre o Instituto Indigenista Interamericano (III), de 1940. ; b) Convênio número 107 da OIT sobre Populações Indígenas e Tribais em Países Independência, de 1957” (p. 14). Tais instrumentos foram adotados em meados do século XX, inseridos no contexto do indigenismo integracionista, na condição de minoria tutelada pelo

${ }^{8}$ Hooker (2009). Disponível em: http://unesdoc.unesco.org Acesso em: 10/12/2015. 
Estado, e propunham como objetivo alcançar o desenvolvimento e a integração indígena ao Estado e ao mercado.

Entretanto, em 1968, de acordo com Caleffi (2004) veio a público um terceiro posicionamento que sinalizou a emancipação dos povos indígenas e a compreensão da multiculturalidade como um fator constitutivo dos próprios estados-nação latino-americano, e não como uma etapa passageira da sua história. Neste posicionamento houve outros dois instrumentos internacionais sociais que fundamentaram as políticas afirmativas para os povos indígenas nas últimas décadas: “a) o Convênio número 169 da OIT sobre Povos Indígenas e Tribais em Países Independentes, de 1989; b) a Declaração das Nações Unidas sobre os Direitos dos Povos Indígenas, de 2007” (Fajardo, 2010, p. 14).

Neste contexto, o Convênio no 169 da OIT sobre Povos Indígenas e Tribais em Países Independentes, de 1989 "rompeu explicitamente com o integracionismo e estabeleceu suas bases de um modelo pluralista, baseado no controle indígena de suas próprias instituições e modelo de desenvolvimento, e na sua participação nas políticas estatais" (Fajardo, 2010, p. 17).

Sánchez (2011) acrescenta que esse Convênio foi ratificado por 13 países da América Latina e um do Caribe. Na região, dois países, Panamá e El salvador, ainda não substituíram o Convênio 107 pelo 169, razão pela qual o primeiro segue vigente. E adicionalmente, cinco países da região ainda não ratificaram o convênio 169, nem tampouco o anterior. O Chile foi o último país a ratificar o Convênio 169, com um processo que começou em 1993 e foi concluído em 2008. No Panamá há um debate aberto a respeito. Quijano (2005) apresenta algumas justificativas para o aparecimento e fortalecimento do movimento indígena no contexto latinoamericano a partir de 1970,

A tenência de desintegração da estrutura produtiva dos países latino-americanos afetou todos os setores sociais, sobretudo os trabalhadores, produzindo desemprego, subemprego e uma crise de identidade social. Desse modo, aqueles cuja identidade era ambígua tiveram necessidade de buscar novas identificações, indicando a razão de identidades, antes expressadas em termos de classes sociais, redefinirem-se como étnicas, regionais, pobres. (Quijano, 2005, p. 34)

Em busca desta redefinição étnica em quase todos os países da América Latina, as reivindicações indígenas foram classificadas como "reivindicações de minorias" nos dois sentidos do termo "minorias": minoria numérica e minoria sociológica. De maneira geral, as reivindicações dos povos indígenas equivalem-se às demandas dos grupos étnicos, ambas sustentam-se em demandas de igualdade material, direitos coletivos e no objetivo de serem incluídos com a preservação da diferença (igualdade na diversidade; Santos 2001).

Em outras palavras, a perspectiva que demanda igualdade material e social nos Direitos Humanos é plenamente justificada por meio das Ações Afirmativas aos povos indígenas por seu histórico de genocídio, etnocídio, políticas de exclusão, assimilação e discriminação. Um histórico de atividades, sobretudo estatais, que explicam porque a mera igualdade perante a lei não é suficiente. Ou seja, o paradigma individualista liberal do direito ocidental só gerou exclusão aos povos indígenas. A fórmula individualista de consagração de direitos ao cidadão uno, nunca incluiu os povos indígenas. Muito pelo contrário, negou-lhes a existência enquanto "coletividade", para integrá-los na fórmula totalizante "individualidade".

Finalmente, com a promulgação em 2007, da Declaração das Nações Unidas sobre os Direitos dos Povos Indígenas, os povos indígenas tiveram seus direitos resguardados enquanto coletividades, tendo liberdade para definir sua condição política e seu modelo de desenvolvimento, assim como a participar da tomada de decisões com o Estado, se assim desejarem.

Já Fajardo (2006) aponta que em relação às reformas constitucionais com exceção do Chile, todos os países andinos mudaram a Constituição reconfigurando a relação jurídica entre os Estados e os povos indígenas. Dentre eles destaca a Colômbia em 1991, o Peru em 1993, a 
Bolívia em 1994-2007, o Equador em 1998 e 2008, e a Venezuela em 1999. Entre tais reformas, cabe ressaltar as que seguem:

a) o reconhecimento do caráter pluricultural do Estado/nação/república, e o direito à identidade cultural, individual e coletiva. o que permite superar a ideia de Estado-nação monocultural e monolíngue. b) o caráter do sujeito político dos povos e comunidades indígenas e campesinas nos quais os povos indígenas têm direito ao controle das suas instituições políticas, culturais e sociais e seu desenvolvimento econômico, o que permite superar o tratamento tutelar desses povos, como objeto de políticas que ditam terceiros. (Fajardo, 2006, p. 539)

Como exemplo das reformas ocorridas, Sánchez citado por Fajardo menciona a Colômbia, que "a partir da Constituição de 1991, criou numerosas leis, medidas e dotação orçamentária, para os indígenas que se aproximam de $2 \%$ da população total do país e ocupam quase um quarto do território nacional” (2010, p. 98). Além disso, houve a garantia representação direta de indígenas no Congresso.

Por sua vez, na Bolívia, as políticas direcionadas para as populações indígenas não obtiveram avanços significativos nos últimos anos. Fajardo salienta que:

Desde os anos oitenta a Bolívia tem vivido o impacto de políticas neoliberais de ajuste estrutural, que levaram ao empobrecimento da população em geral e da indígena em particular. Tais políticas desembocaram nas "três guerras" pela água (2000), pelo gás (2003) e pela nacionalização do petróleo (2005), que conseguiram o "fim do experimento neoliberal" e uma mudança política do país como um todo. (Fajardo, 2010, p. 40)

No que tange à educação superior Hooker apud Unesco (2015) apresenta na América Latina, as experiências existentes quanto à oferta diferenciada ou não para povos indígenas atendeu algumas expectativas das diferentes etnias nos diversos países. Porém essas políticas afirmativas atingiram uma parcela mínima destes povos por falta de políticas públicas específicas, como é o caso do Brasil.

Conforme Cordeiro (2008) durante as palestras proferidas no I e II Seminários Internacionais "Povos Indígenas e Sustentabilidade: saberes e práticas interculturais na universidade", realizados em Campo Grande (MS), nos meses de agosto de 2006 e 2007, foram apresentadas experiências no ensino superior para povos indígenas do México, Chile, Paraguai, Peru e da Bolívia, muitas das quais classificadas como ações afirmativas elaboradas e executadas com o apoio da Fundação Ford. Fato que chama atenção e que merece reflexão neste aspecto, é que as ações afirmativas nesses países foram financiadas por meio de recursos privados, de uma fundação pertencente a uma empresa multinacional - nesse caso a Fundação Ford - que vem investindo números expressivos nos países em desenvolvimento.

A Fundação Ford (2015) é uma organização privada, sem fins lucrativos, criada em 1936 nos Estados Unidos e que tem como objetivo "ser uma fonte de apoio a pessoas e instituições inovadoras em todo o mundo, comprometidas com a consolidação da democracia, a redução da pobreza e da injustiça social e com o desenvolvimento humano".

De acordo com Benati (2008) a Fundação Ford foi e ainda é uma das grandes agências financiadoras de pesquisas em ações afirmativas, com destinação de bolsa de estudos para cursos de pós-graduação, inclusive nas universidades públicas no Brasil. A autora cita como exemplos a universidade da cidadania Zumbi dos Palmares, apoiada na iniciativa de uma organização nãogovernamental (ONG), bem como a pós-graduação lato sensu na Faculdade de Educação da Universidade Federal Fluminense (UFF) e o Laboratório de Políticas Públicas (LPP) da Universidade Estadual do Rio de Janeiro (UERJ).

\footnotetext{
${ }^{9}$ Oficial da Fundação Ford (2015). Disponível em: http://www.fordfound.org/ Acesso em 17/01/2015.
} 
Dessa maneira, observamos que os investimentos realizados pela fundação nos países em desenvolvimento, seguem orientações dos organismos internacionais como o Banco Mundial (BM) e Fundo Monetário Internacional (FMI) visando à manutenção da ordem social, apoiandose na educação, em particular nas ações afirmativas, como suporte para essas diretrizes.

Segundo Cordeiro (2008, p. 45) "mesmo com financiamento externo, as dificuldades enfrentadas pelos indígenas nos países da América Latina são iguais. Ou seja, ter acesso ao ensino superior é um privilégio e permanecer neste, um desafio maior ainda". No relato dos representantes indígenas dos países como México, Chile, Paraguai, Peru e da Bolívia, durante os I e II Seminários Internacionais "Povos Indígenas e Sustentabilidade: saberes e práticas interculturais na universidade", a autora salientou que o atendimento do ensino superior para a população em geral não atinge índices desejáveis, mas tem bons resultados; porém os indígenas se encontram em situação de maior desvantagem, considerando o fato de geograficamente estarem mais distantes das universidades (geralmente na zona rural) e o problema da qualidade da educação recebida nos níveis de ensino anteriores, somados a língua.

Estudos realizados por outros autores (Lopes; Sichra, 2006 - Bolívia; Schmelkes, 2006 México) validam a afirmação de Cordeiro (2008) e indicaram que além dos problemas mencionados, após o ingresso por meio de programas de ações afirmativas, os indígenas desses países também enfrentaram problemas de permanência. Alguns abandonaram os estudos por dificuldades de ordem econômica, devido à precariedade da situação econômica da família, e outros por questões acadêmicas.

Turner (2006) considera ainda que no ensino superior a situação é grave, pois iniciativas de ações afirmativas na América Latina estão presentes em poucas universidades e na área da educação básica, constataram-se graus críticos de carência educacional de crianças indígenas, porque "nas salas de aula, crianças indígenas raramente são respeitadas como indivíduos criativos e inteligentes, mesmo quando seus professores primários são indígenas". (Turner, 2006, p. 201)

Em complemento Fajardo acrescenta que "os serviços públicos destinados aos indígenas, como educação bilíngue intercultural e saúde, não melhoraram sua qualidade nem cobertura de modo suficiente. Isto não apenas deve-se à falta de fundos, mas à inércia burocrática” (2010, p. 38). Como exemplo, a autora cita o fundo destinado à educação bilíngue intercultural do Peru, que no ano de 2007 executou somente 30\% da demanda educativa no setor.

Entretanto, também tivemos alguns avanços. No México foram criadas algumas universidades interculturais abertas,

Universidades interculturais abertas se tornaram espaços privilegiados para o diálogo entre culturas, orientação curricular flexível, acesso diferenciado aos critérios acadêmicos e combinação de programas de apoio acadêmico (bolsas). Enfim, ocorre a transformação da Instituição que os recebe por meio da criação, de mecanismos que evitam o abandono dos estudos por qualquer razão.

(Schmelkes, 2006, p. 125)

Em relação à proposta de universidades interculturais abertas ${ }^{10}$ Fajardo (2010) salienta que mesmo a iniciativa sendo válida porque trata de uma educação superior indígena, esta não foi aceita, por diversos motivos, no Equador e Chile, pois faltaram programas formativos conduzidos pelos próprios indígenas, que tivessem qualidade e desenvolvessem capacidades para a interação e o diálogo intercultural. Em contraponto o Equador elaborou:

\footnotetext{
${ }^{10}$ Algumas destas universidades aparecem na lista do Programa Internacional de Intercâmbio em multiculturalismo, pluralismo jurídico e direitos indígenas. Para aprofundamentos nessas temáticas está disponível em: www.alertanet.org/programa.htm acesso em: 16/10/2016.
} 
Um estrado para formação de líderes realizado em FLACSO ${ }^{11}$ Equador, com a colaboração do fundo Indígena, para formar lideres das principais organizações indígenas da região. Tal espaço lhes permitiu uma formação sistemática e o intercâmbio de experiências. (Fajardo, 2010, p. 53)

Já no Chile a autora acrescenta que houve programas de bolsas de estudos para indígenas com um investimento de 45 milhões de dólares. Esse programa de bolsa de estudos constituiu um mecanismo de acesso de caráter individual. Ou seja, tal programa não se vinculou aos projetos de desenvolvimento dos povos indígenas e não teve políticas de acesso mais amplas a todos os estudantes índios. (Fajardo, 2010, p. 55)

Em outro estudo realizado por Fajardo (2010) e Schmelkes (2006) foi diagnosticado, que além do acesso ao ensino superior ser difícil para a população indígena da América Latina, a profissionalização, a formação em direitos indígenas e multiculturalismo dos servidores públicos e juízes também é precária. Tampouco há cursos que permitam o desenvolvimento de capacidades para a prestação de serviços públicos com pertinência étnico-cultural de modo sistemático.

Isso explica, em parte, a falta de ferramentas nas instituições públicas para organizar sua ação com base nos direitos. Muito poucas universidades da região oferecem programas ou cursos sobre direitos indígenas, ainda que haja uma quantidade importante delas interessadas em introduzir ou desenvolver tal temática, quase nenhuma faculdade de direito oferece um curso sobre direitos indígenas como parte do programa obrigatório. O mesmo problema se observa na formação especializada que oferecem instituições como as academias da magistratura e outras entidades encarregadas pela formação ou capacitação de juízes, fiscais, policiais ou servidores públicos. (Fajardo, 2010, p. 66)

Em contraponto, Fajardo (2006, p. 567) apresentou no mesmo estudo algumas práticas afirmativas na América Latina a serem consideradas,

a) No México, que tem larga tradição indigenista, existe maior concentração na oferta formativa sobre povos indígenas, principalmente no que refere a direitos indígenas. Dentre as principais universidades estão: Universidade Nacional Autônoma do México (UNAM) que oferta graduações, especializações e mestrados; Universidade de Michocán (CIESAS) com cursos de graduação na área de direito consuetudinário indígena.

b) $\mathrm{Na}$ Guatemala, por meio de um convênio entre a Universidade Nacional Autônoma do México (UNAM) e a Universidade de São Carlos (USAC) ministram-se graduação, especialização e mestrado em Direito Consuetudinário Indígena para funcionários, juízes e dirigentes indígenas.

c) Na Venezuela, a Universidade de Zulia, ministra uma Graduação em Direitos Indígenas e Gênero. Também a Lei Orgânica de Povos e Comunidades Indígenas (LOPCI) ordena a criação de cursos de formação para funcionários em matéria de direitos indígenas, antropologia jurídica, pluralismo, etc. A LOPCI estabelece que o Estado organize programas de capacitação para os funcionários públicos que trabalhem em terras indígenas. Estabelece ainda a mesma obrigação de formação para membros de empresas privadas que operam em território indígena, de forma que conheçam o direito e a cultura desses povos. No caso específico de juízes, também se prevê a formação em direito indígena e pluralismo jurídico.

d) No Peru, a Pontifícia Universidad Católica (PuCP) oferece o mestrado em Direitos Humanos e um curso sobre povos indígenas;

\footnotetext{
${ }^{11}$ La Facultad Latinoamericana de Ciencias Sociales (FLACSO) es una organización intergubernamental regional autónoma para América Latina y el Caribe, dedicada a la investigación, docencia y difusión de las ciencias sociales.
} 

indígenas.

e) Na Argentina, a Universidade de Buenos Aires oferta um curso sobre direitos

Entretanto, Hall e Patrinos citados por $\operatorname{UNESCO}(2005$, p.16) afirmam que "apesar da América Latina ter reconhecido direitos a nível internacional e nacional dos povos indígenas, efetivamente na prática cumpre-se muito pouco". No estudo realizado por esses autores diagnosticou-se que mesmo com as conquistas alcançadas nos últimos 25 anos, os povos indígenas da América Latina avançaram pouco em matéria econômica e social durante as duas últimas décadas e continuam sofrendo altos níveis de pobreza, menor educação e maior incidência de enfermidades e discriminação que outros grupos sociais desfavorecidos.

\section{Reflexões Finais: Para Continuar a Pensar...Lutar... Quem Sabe Mudar de Perspectiva?}

Discutir ações afirmativas na América Latina é um campo espinhoso, ainda mais quando se trata de realizar esta discussão num estado neoliberal de direito. Nesta trajetória de discussão vamos encontrar muitos opositores dessas ações. Tais opositores compartilham um profundo desprezo pelas pesquisas numéricas sobre a desigualdade racial e étnica na América Latina. Para Munanga (2006, p. 57) "as polêmicas e as controvérsias a respeito dessas políticas são indicadores das realidades de uma sociedade que ainda vive e confunde os mitos e os fatos". Ou seja, uma sociedade na qual o mito funciona como realidade.

Nesta trajetória vamos encontrar aqueles que defendem um humanismo ou universalismo abstrato que utiliza como slogan "perante a lei todos somos iguais!". Este mesmo grupo sustenta que a categoria raça não existe e que foi inventada para oprimir os negros. Para tal grupo, as melhores políticas públicas são as macrossociais. Qualquer proposta de ação afirmativa que introduza diferenças biológicas, para lutar contra desigualdades, é considerada nessa abordagem, o reconhecimento oficial das raças num contexto que apresenta como característica dominante a mestiçagem. Entendem que as propostas que defendem o reconhecimento das diferenças raciais podem causar "a mudança na paz propiciada pela democracia racial". (Munanga, 2006). Hasenbalg (1979) complementa,

O mito da democracia racial não só implicou uma "reconstrução idílica" do passado e da persistência do clientelismo, como também foi sustentado pelas realidades sociais do período republicano inicial - a falta de discriminação legal, a presença de alguns nãobrancos dentro da elite e a ausência de conflito racial declarado. Por sua vez, a comparação frequente dessas realidades com a situação racial de outras sociedades, particularmente dos Estados Unidos, ajudava a moldar a auto-imagem favorável dos brasileiros com referência às relações raciais. (p. 242)

Estas objeções tornam-se mais contundentes quando se referem às políticas que envolvem o acesso ao ensino superior. Neste caso, os opositores apresentam dois argumentos: a solução para o problema das pessoas negras e índias serem representadas por pequeno número no corpo discente das universidades brasileiras públicas e privadas é o investimen to no ensino público. O segundo diz respeito ao nível de conhecimentos dos candidatos. Para este grupo, o acesso de pessoas negras ou indígenas à universidade via políticas de ação afirmativa comprometeria o nível acadêmico. (Almeida, 2007, p. 26)

Neste posicionamento que envolve o nível acadêmico, percebemos a questão espinhosa da meritocracia, que logo se transforma em mérito acadêmico. Ditos de outra forma, os opositores das políticas de ação afirmativa, desconsideram a construção do saber partilhada com segmentos historicamente desprivilegiados - índios, negros, deficientes, carentes - insistindo que tais saberes não possuem nem valor nem utilidade dentro da universidade, embora seus textos acadêmicos preguem o multiculturalismo e o pluralismo étnico-racial-social. Este mesmo grupo 
resiste à presença destes alunos dentro da academia, fazendo questão de ignorar a diversidade, mantendo suas práticas de ensino.

Em relação a estas objeções o posicionamento adotado por militantes antirracistas se contrapõe a estes argumentos, pois se utilizam o entendimento de raça como um conteúdo social e político e não como um marcador genético. Ou seja, está comprovado por meio de pesquisas geneticistas que não existem raças puras ou estanques. Portanto, não há como a política de cotas desfazer a mistura racial comprovada pela genética humana. Porém, se para o geneticista humano, a raça não existe, ela existe na cabeça dos racistas e suas vítimas. A discriminação que negros e índios são vítimas apesar da mistura de sangue não resulta apenas de uma questão econômica que atinge todos os pobres da sociedade, mas sim de uma discriminação racial camuflada. Neste sentido, o problema central não está na categoria raça, mas no racismo que "hierarquiza, desumaniza e justifica a discriminação existente no país". (Munanga, 2006, p. 48)

Visto sob este prisma, os defensores que se pautam na defesa racial, afirmam que implantar políticas de ações afirmativas para negros e índios, não só no sistema educativo superior, mas em todos os setores da vida social latino-americana, nos quais negros e índios são discriminados, não significa destruir a identidade nacional, nem tampouco a mistura racial. Significa sim, construir uma identidade nacional plural ou étnica, na qual os negros, índios, mulheres, deficientes entre outros possam participar em igualdade de acesso no processo de construção de seus países.

Há outro grupo de defensores, porém, que utilizam a posição do "antirracismo de diferença", que visa o reconhecimento público das diferenças raciais e sociais, sob a execução de um programa étnico-cultural pautado nos direitos coletivos prevalecendo sobre os direitos individuais. "Trata-se de uma demanda de justiça que se refere à igualdade de tratamento, e que com razão ou sem razão, se baseia na convicção de que os direitos individuais não são suficientes para assegurarem sozinhos, o reconhecimento específico" (Munanga, 2006, p. 54). Porém, para este autor, tal postura traz uma posição problemática, pois obriga a tornar as diferenças salientes, em todas as circunstâncias, obrigando em negar as semelhanças, além de não sugestionar como os direitos coletivos vão conviver com os direitos individuais num mesmo estado democrático.

A perspectiva que adotamos neste texto (e na vida) compactua que todas as culturas são dinâmicas e não se defende sob hipótese alguma que as culturas indígenas devam ficar em nichos vivendo isoladas. O mundo atual demanda por espaços autênticos de convivência entre os diferentes, mas para isso são necessários espaços com investimentos considerados adequados por cada comunidade, nos quais as culturas possam reproduzir seu modo de ser, viver a sua cosmologia, de forma integral e não fraturada.

É neste cenário que ocorrem as discussões em torno das ações afirmativas. Segundo Cordeiro (2008, p. 37), os argumentos contrários geralmente são: a) de inconstitucionalidade, por ferir o princípio de igualdade; b) de o verdadeiro problema ser social e não racial; c) de não ter dado certo nos Estados Unidos porque o racismo lá não foi extinto.

Em relação ao primeiro argumento alegando que as ações afirmativas são inconstitucionais, pois ferem o princípio da igualdade de todos perante a lei, Campos e Feres Júnior (2014) consideram este um argumento "falacioso, quando não reacionário" (p. 109). Tal autor apresenta que boa parte das nações do mundo atual combinam, em suas respectivas constituições, preceitos universais válidos para todos os cidadãos com dispositivos que visam garantir os direitos específicos para grupos desfavorecidos ou então discriminados.

$\mathrm{Na}$ realidade, o que percebemos é que as ações afirmativas vão contra o ideário neoliberal, inclusive no campo do Direito, e por isso são tão criticadas. Entretanto, ao se analisar os vários instrumentos e convenções internacionais aqui citados, visualizamos que este trazem vários mecanismos que apontam na direção de ações afirmativas, como por exemplo: a) reserva de vagas para portadores de deficiência física em concursos públicos; b) a imposição junto a partidos políticos de um percentual mínimo de candidatas mulheres na eleição geral; c) a vigência de estatutos de proteção específicos: do idoso, da criança e do adolescente entre outros. 
Por sua vez, o segundo argumento apresentado pelos opositores às ações afirmativas na América Latina refere-se à alegação de que o verdadeiro problema ser social e não racial. Neste posicionamento concordamos haver uma parcela de veracidade. Os problemas sociais na América Latina realmente são graves. Porém, geralmente a parcela mais pobre da população latino-americana que sofre problemas sociais de toda ordem, são negros e índios. Desta forma, lutar contra o racismo camuflado na América Latina, por meio de acesso a direitos específicos, não anula a luta contra as desigualdades presentes nas estruturas sociais e também no cotidiano, apenas fortalece estas minorias que terão chance de romper com a estigmatização vigente.

Por fim, o terceiro argumento apresentado pelos opositores das ações afirmativas na América Latinas, destaca o fato das mesmas não terem dado certo "nem nos Estados Unidos" isso porque lá o racismo não foi extinto consideramos ser o mais fraco de todos. Os EUA possuem outro contexto, outra realidade, totalmente diferente da América Latina. Lá, o racismo apresenta outras proporções, pois sempre foi "declarado" e não "camuflado" como no contexto latino-americano. Nos EUA o racismo não foi ocultado por trás do mito da democracia racial. Desta forma, quaisquer comparações com aquele país devem ser realizadas com muita cautela e parcimônia.

Especificamente em relação às Ações Afirmativas dos Povos Indígenas, a partir das concepções apresentadas na Organização Internacional do Trabalho (OIT0, percebemos que houve uma quebra do paradigma integracionista mostrando um verdadeiro avanço frente às concepções e às formas como as sociedades indígenas são compreendidas, pelo menos na legislação aplicada na América Latina. Para finalizar... Consideramos que há muito ainda que se refletir... e lutar... E por que não mudar de perspectiva?

\section{Referências}

Almeida, L. F. R. de. (2009). Lutas sociais e questões nacionais na América Latina: Algumas reflexões. Lutas Sociais, 17/18, 64-77.

Almeida, M. M.M. (2007). Ações afirmativas: dinâmicas e dilemas teóricos entre a redistribuição e reconhecimento. II Seminário nacional e movimentos sociais, participação e democracia, 25-27.

Amparo Alves, J. (2009) Young, Brazilian \& Black: Dangerous combination. In: Vida Afrolatina, p. 25-98. Disponível em: https://www.vidaafrolatina.org/ Acesso em: 15 de maio de 2009.

Arendt, H. (1988). As origens do totalitarismo. Documentário.

Beltrão, J. F. (2008). Direitos humanos e povos indígenas: um desafio para a Antropologia. In P. S. W. A. Costa (Coord.) Direitos bumanos em Concreto (pp. 157-174). Juruá.

Benatti, J. H. (2008). A criação de unidades de conservação em áreas de apossamento de populações tradicionais. Novos cadernos $N A E A, 1(2)$.

Bergmann, B. (1996). In defense of affirmative action. Basic Books.

Bezerra, T. T. (2008). Conexões de saberes: o estudo sobre os limites e as possibilidades de uma politica social afirmativa. (Trabalho de Conclusão de Curso, Serviço Social). Universidade de Brasília.

Bobbio, N. (1988). Era dos direitos. Campus.

Caleffi, P. (2004). Educação autóctone nos séculos XVI ao XVIII ou Américo Vespúcio tinha razão. História e memórias da educação no Brasil, 1.

Campos, L. A., \& Feres Júnior, J. (2014). Affirmative action, communitarianism and multiculturalism: necessary or contingent relations? Revista Brasileira de Ciências Sociais, 29(84), 103-118.

Contins, M., \& Sant'ana, L. C. O. (1996). Movimento negro e a questão da ação afirmativa. Estudos Feministas, IFCS/UFRJ-PPCIS/Uerj, 4(1), 209-220.

Cordeiro, M. J. de J. A. (2008). Negros e indígenas cotistas da Universidade Estadual do Mato Grosso do Sul: desempenho acadêmico do ingresso à conclusão de curso. (Tese de Doutorado em Educação). Pontifícia Universidade Católica, São Paulo. 
Fajardo, R. Y. (2010). A modo de introducción. In B. De S. Santos, Refundación del Estado en América Latina: Perspectivas desde una epistemología del Sur. Instituto Internacional de Derecho y Sociedad.

Fajardo, R. Y. (2006). Hitos del reconocimiento del pluralismo jurídico y el derecho indígena em las políticas indigenistas y el constitucionalismo andino. In M. Berraondo (Coord.), Pueblos Indígenas y derechos bumanos (pp. 537-567). Universidad de Deusto.

Flores, J. H. Direitos bumanos, interculturalidade e racionalidade de resistência. (mimeo)

Godinho, T. (1996). Ação afirmativa no Partido dos Trabalhadores. Estudos Feministas, 4, (1), $148-157$.

Guimarães, A. S. A. (1997). A desigualdade que anula a desigualdade: Notas sobre a ação afirmativa no Brasil. In: J. Souza (Org.). Multiculturalismo e racismo: Uma comparação Brasil Estados Unidos (pp. 233-242). Paralelo 15.

Harvey, D. A. (2005). A brief history of neoliberalism. Oxford University Press.

Hasenbalg, C. A. (1979). Discriminação e desigualdades raciais no Brasil. Graal.

Jaccoud, L.; Theodoro, M. (2005). Raça e educação: os limites das políticas universalistas. Ações afirmativas e combate ao racismo nas Américas, 1.

Klein, N. (2007). The shock doctrine: The rise of disaster capitalism. Henry Holt \& Company.

López, L. E.\& \& Sichra, I. (2008). Intercultural bilingual education among indigenous peoples in Latin America. In: Encyclopedia of language and education (pp. 1732-1746). Springer.

Moehlecke, S. (2000). Propostas de ações afirmativas para o acesso da população negra ao ensino superior no Brasil: Experiências e debates. In: Programa a Cor da Babia. A Educação e os afro-brasileiros (pp. 167-181). UFBA; Ford Foundation; Novos Toques.

Munanga, K. O. (1996). Anti-racismo no Brasil. In: K. Munanga (Org.), Estratégias e políticas de combate à discriminação racial (pp. 79-111). Edusp.

Munanga, K. O. (2006). Algumas considerações sobre "raça", ação afirmativa e identidade negra no Brasil: fundamentos antropológicos. Revista USP, 68, 46-57.

Oliven, A. C. (2009). Ações afirmativas na Universidade Federal do Rio Grande do Sul e o seu significado simbólico. Educação (UFSM), 34(1), 65-76.

Piovesan, F. (2005). Ações afirmativas da perspectiva dos direitos humanos. Cadernos de Pesquisa, 35(124), jan./abr., 43-55.

Quijano, A. (2005). El "movimiento indígena” y las cuestiones pendientes en América Latina. Revista Tareas, Panamá: CELA - Centro de Estudios Latinoamericanos, 119, 31-62.

Ramos, T. T. (2003). A geografia dos conflitos sociais na América Latina e no Caribe. Informe final do Curso de Movimentos Sociais e Novos Conflitos na América Latina e no Caribe. Programa Regional de Becas da CLASCO.

Sánchez, J. A. (2011). Territórios ancestrais afro-equatorianos: uma proposta para o exercício da autonomia territorial e dos direitos coletivos. Revista da Associação Brasileira de Pesquisadores/as Negros/as (ABPN), 1(3), 13-52.

Santos, B. de. S. (2003). Reconhecer para libertar: Os caminhos do cosmopolitanismo multicultural. Civilização Brasileira.

Santos, B. de. S. (2001). El significado político y jurídico de la jurisdicción indígena. In: B. De S. Santos \& M. Garcíavillegas (Orgs.), El caleidoscópio de las justicias en Colômbia. Bogotá: Siglo del Hombre Editores.

Santos, H. et al. (1999). Políticas públicas para a população negra no Brasil. [Relatório]. ONU.

Santos, S. A. dos (Org.) (2005). Ações afirmativas e combate ao racismo nas Américas. Ministério da Educação/Secretaria de Educação Continuada, Alfabetização e Diversidade.

Silva Freitas, M. C. da. (2010). O olhar da UNESCO sobre o exercício da tolerância e do respeito às diferenças (1946-2001). La Recherche en education, 3, 105-145.

Siqueira, A. C. de. (2004). The regulation of the commercial approach to the educational sector by WTO/GATS. Revista Brasileira de Educação, 26, 145-156.

Schmelkes, S. (2006). La interculturalidad en la educación básica. Revista Prelac, 3, 120-127. 
Sousa, A. L. (2009). Educação e igualdade na América Latina: A questão da discriminação racial. Campanha Latino Americana pelo Direito à Educação.

Turner, M. (2006). Talking with children and young people about death and dying. Jessica Kingsley Publishers.

Wedderburn, C. M. (2005). Do marco histórico das políticas públicas de ações afirmativas perspectivas e considerações. In: S. A. Dos Santos (Org.), Ações afirmativas e combate ao racismo nas Américas pp. 313-396). Ministério da Educação/Secretaria de Educação Continuada, Alfabetização e Diversidade.

\section{Sobre os Autores}

\section{Juliane Sachser Angnes}

Universidade Estadual do Centro-Oeste do Paraná (UNICENTRO)

Programa de Pós-Graduação em Educação (PPGE UNICENTRO)

Programa de Pós-Graduação em Administração (PPGADM UNICENTRO)

julianeangnes@gmail.com

https://orcid.org/0000-0002-4887-7042

Graduação em Secretariado Executivo Bilíngue e em Letras - Português/Inglês pela Universidade Estadual do Oeste do Paraná (UNIOESTE). Especialista em Linguística Aplicada e Mestre em Letras - Linguagem e Sociedade também pela UNIOESTE. Doutora em Educação pela Universidade Federal do Paraná (UFPR), linha de Cognição,

Desenvolvimento Humano e Aprendizagem. Realizou estágio pós-doutoral no Programa de Pós-Graduação em Administração da Universidade Estadual de Maringá (UEM) no Grupo de Pesquisas em Estudos Organizacionais. É professora da Universidade Estadual do Centro-Oeste (UNICENTRO) vinculada ao Departamento de Secretariado Executivo e aos Programas de Pós-Graduação em Administração (Mestrado Profissional) e Pós-Graduação em Educação (Mestrado e Doutorado). Tem experiência na docência e pesquisa nas áreas de Educação e Administração, atuando principalmente nas seguintes áreas temáticas: educação escolar indígena; comunicação organizacional; redes solidárias; economia do bemestar social; gestão escolar; planejamento e organização de eventos; cerimonial e protocolo; etiqueta social e comportamental; redação técnica oficial e empresarial; responsabilidade social; pesquisa qualitativa em Ciências Sociais Aplicadas.

\section{Elisa Yoshie Ichikawa}

Universidade Estadual de Maringá (UEM)

Programa de Pós-Graduação em Administração (PPA UEM)

eyichikawa@,uem.br

https://orcid.org/0000-0001-7096-7653

Graduação em Administração pela Universidade Estadual de Londrina (UEL), mestrado em Administração pela Universidade Federal de Santa Catarina (UFSC) e doutorado em Engenharia de Produção também pela Universidade Federal de Santa Catarina (UFSC).

Realizou estágio pós-doutoral no Centro de Pós-Graduação e Pesquisas em Administração da Universidade Federal de Minas Gerais (CEPEAD/UFMG). Suas investigações atualmente envolvem os estudos organizacionais em temas como cotidiano, identidades, discursos, memória e história, a partir de dimensões sociológicas, simbólicas e qualitativas de análise.

\section{Marcel Luciano Klozovski}

Universidade Estadual do Centro-Oeste do Paraná (UNICENTRO)

Professor do Departamento de Administração (UNICENTRO)

marcelklozovski@gmail.com

http://orcid.org/0000-0002-9810-6537 
Doutor em Administração na Universidade Estadual de Maringá (UEM). Mestre em Contabilidade pela Universidade Federal do Paraná (UFPR). Especialista pela ESAP de Londrina com ênfase em Administração Financeira. Graduado em Administração pela Universidade Estadual de Ponta Grossa e em Ciências Contábeis pela Unicesumar - Maringá. Atua nas áreas de logística, gestão estratégica, gestão de custos, pesquisa de mercado e administração financeira como professor do Departamento de Administração da Universidade Estadual do Centro Oeste (UNICENTRO) situada na cidade de Guarapuava, estado do Paraná.

\section{Maria de Fátima Quintal de Freitas}

quintal.fatima@gmail.com

https://orcid.org/0000-0002-0414-199X

Professora Associada do Programa de Pós-Graduação em Educação da UFPR, Curitiba-PR. Mestre e Doutora em Psicologia Social (PUC-SP) e Pós-Doutora em Psicologia Comunitária (ISPA, Lisboa e Univ. Porto, Portugal).

\section{Sobre o Editores}

\section{Juliane Sachser Angnes}

Universidade Estadual do Centro-Oeste do Paraná (UNICENTRO)

Programa de Pós-Graduação em Educação (PPGE UNICENTRO)

Programa de Pós-Graduação em Administração (PPGADM UNICENTRO)

julianeangnes@gmail.com

https://orcid.org/0000-0002-4887-7042

Graduação em Secretariado Executivo Bilíngue e em Letras - Português/Inglês pela

Universidade Estadual do Oeste do Paraná (UNIOESTE). Especialista em Linguística Aplicada e

Mestre em Letras - Linguagem e Sociedade também pela UNIOESTE. Doutora em Educação pela Universidade Federal do Paraná (UFPR), linha de Cognição, Desenvolvimento Humano e Aprendizagem. Realizou estágio pós-doutoral no Programa de Pós-Graduação em

Administração da Universidade Estadual de Maringá (UEM) no Grupo de Pesquisas em Estudos Organizacionais. É professora da Universidade Estadual do Centro-Oeste (UNICENTRO) vinculada ao Departamento de Secretariado Executivo e ao Programa de Pós-Graduação em Administração (Mestrado Profissional). Tem experiência na docência e pesquisa nas áreas de Educação e Administração, atuando principalmente nas seguintes áreas temáticas: comunicação organizacional; redes solidárias; economia do bem-estar social; gestão escolar; planejamento e organização de eventos; cerimonial e protocolo; etiqueta social e comportamental; redação técnica oficial e empresarial; responsabilidade social; pesquisa qualitativa em Ciências Sociais Aplicadas.

\section{Kaizô Iwakami Beltrão}

EBAPE FGV - - Escola Brasileira de Administração Pública e de Empresas

Kaizo.beltrao@,fgv.br http://orcid.org/0000-0002-3590-8057

Graduação em Engenharia Mecânica pelo Instituto Tecnológico de Aeronáutica (1974), mestrado em Matemática Aplicada pelo Instituto de Matemática Pura e Aplicada (1977) e doutorado em Estatística pelo Departamento de Estatística da Princeton University (1981). Atualmente é Pesquisador/Professor da EBAPE/FGV-RJ e responsável técnico pelos relatórios técnicos do ENADE junto ao INEP através da Fundação Cesgranrio. Tem experiência na área de População e Políticas Públicas, com ênfase em Previdência Social e Educação, atuando principalmente nos seguintes temas: bases de dados para políticas públicas, avaliações educacionais, diferenciais por sexo/raça, condições de saúde, demografia (modelagem estatística) e mortalidade. 


\section{Dossiê Especial \\ Educação e Povos Indígenas: Identidades em Construção e Reconstrução arquivos analíticos de políticas educativas}

ISSN 1068-2341

\section{(9) (1) (2)}

Los/as lectores/as pueden copiar, mostrar, distribuir, y adaptar este articulo, siempre y cuando se de crédito y atribución al autor/es y a Archivos Analíticos de Políticas Educativas, los cambios se identifican y la misma licencia se aplica al trabajo derivada. Más detalles de la licencia de Creative Commons se encuentran en https://creativecommons.org/licenses/by-sa/4.0/. Cualquier otro uso debe ser aprobado en conjunto por el autor/es, o AAPE/EPAA. La sección en español para Sud América de AAPE/EPAA es publicada por el Mary Lou Fulton Teachers College, Arizona State University y la Universidad de San Andrés de Argentina. Los artículos que aparecen en AAPE son indexados en CIRC (Clasificación Integrada de Revistas Científicas, España) DIALNET (España), Directory of Open Access Journals, EBSCO Education Research Complete, ERIC, Education Full Text (H.W. Wilson), PubMed, QUALIS A1 (Brazil), Redalyc, SCImago Journal Rank, SCOPUS, SOCOLAR (China).

Por errores y sugerencias contacte a Fischman@asu.edu

Síganos en EPAA's Facebook comunidad at https://www.facebook.com/EPAAAAPE y en Twitter feed@epaa_aape. 


\section{arquivos analíticos de políticas educativas conselho editorial}

Editor Consultor: Gustavo E. Fischman (Arizona State University)

Editoras Coordenadores: Marcia Pletsch, Sandra Regina Sales (Universidade Federal Rural do Rio de Janeiro) Editores Associadas: Andréa Barbosa Gouveia (Universidade Federal do Paraná), Kaizo Iwakami Beltrao, (EBAPE/FGVI), Sheizi Calheira de Freitas (Federal University of Bahia), Maria Margarida Machado, (Federal University of Goiás / Universidade Federal de Goiás), Gilberto José Miranda, (Universidade Federal de Uberlândia)

\author{
Almerindo Afonso \\ Universidade do Minho \\ Portugal \\ Rosanna Maria Barros Sá \\ Universidade do Algarve \\ Portugal
}

\section{Maria Helena Bonilla}

Universidade Federal da Bahia

Brasil

Rosa Maria Bueno Fischer

Universidade Federal do Rio Grande

do Sul, Brasil

\section{Alice Casimiro Lopes}

Universidade do Estado do Rio de

Janeiro, Brasil

\section{Suzana Feldens Schwertner}

Centro Universitário Univates

Brasil

Geovana Mendonça Lunardi

Mendes Universidade do Estado de Santa Catarina

\section{Flávia Miller Naethe Motta}

Universidade Federal Rural do Rio de Janeiro, Brasil

\section{Alexandre Fernandez Vaz \\ Universidade Federal de Santa \\ Catarina, Brasil \\ Regina Célia Linhares Hostins \\ Universidade do Vale do Itajaí, Brasil}

\section{Alfredo Macedo Gomes \\ Universidade Federal de Pernambuco \\ Brasil}

\section{Jefferson Mainardes}

Universidade Estadual de Ponta

Grossa, Brasil

\section{Jader Janer Moreira Lopes}

Universidade Federal Fluminense e

Universidade Federal de Juiz de Fora,

Brasil

\section{Debora Nunes}

Universidade Federal do Rio Grande do Norte, Brasil

\author{
Alda Junqueira Marin \\ Pontifícia Universidade Católica de \\ São Paulo, Brasil \\ Dalila Andrade Oliveira \\ Universidade Federal de Minas \\ Gerais, Brasil
}

José Augusto Pacheco

Universidade do Minho, Portugal

\author{
Jane Paiva \\ Universidade do Estado do Rio de \\ Janeiro, Brasil
}

\section{Paulo Alberto Santos Vieira}

Universidade do Estado de Mato

Grosso, Brasil

Fabiany de Cássia Tavares Silva Universidade Federal do Mato

Grosso do Sul, Brasil

\section{António Teodoro}

Universidade Lusófona

Portugal

\section{Lílian do Valle}

Universidade do Estado do Rio de Janeiro, Brasil

\section{Alfredo Veiga-Neto \\ Universidade Federal do Rio Grande do Sul, Brasil}




\section{archivos analíticos de políticas educativas consejo editorial}

Editor Consultor: Gustavo E. Fischman (Arizona State University)

Coordinador (Español / Latinoamérica): Ignacio Barrenechea, Axel Rivas (Universidad de San Andrés Editor Coordinador (Español / Norteamérica): Armando Alcántara Santuario (Universidad Nacional Autónoma de México)

Editor Coordinador (Español / España): Antonio Luzon (Universidad de Granada)

Editores Asociados: Felicitas Acosta (Universidad Nacional de General Sarmiento), Jason Beech ( Universidad de San Andrés), Angelica Buendia, (Metropolitan Autonomous University), Alejandra Falabella (Universidad Alberto Hurtado, Chile), Carolina Guzmán-Valenzuela (Universidade de Chile), Cesar Lorenzo Rodriguez

Uribe (Universidad Marista de Guadalajara, María Teresa Martín Palomo (University of Almería), María Fernández Mellizo-Soto (Universidad Complutense de Madrid), Tiburcio Moreno (Autonomous Metropolitan University-Cuajimalpa Unit), José Luis Ramírez, (Universidad de Sonora), Maria Veronica Santelices (Pontificia Universidad Católica de Chile)

Claudio Almonacid

Universidad Metropolitana de

Ciencias de la Educación, Chile

Miguel Ángel Arias Ortega

Universidad Autónoma de la

Ciudad de México

Xavier Besalú Costa

Universitat de Girona, España

Xavier Bonal Sarro Universidad Autónoma de Barcelona, España

\author{
Antonio Bolívar Boitia \\ Universidad de Granada, España
}

José Joaquín Brunner

Universidad Diego Portales, Chile

Damián Canales Sánchez

Instituto Nacional para la

Evaluación de la Educación,

México

Gabriela de la Cruz Flores

Universidad Nacional Autónoma de México

Marco Antonio Delgado Fuentes

Universidad Iberoamericana,

México

Inés Dussel, DIE-CINVESTAV, México

Pedro Flores Crespo Universidad Iberoamericana, México
Ana María García de Fanelli

Centro de Estudios de Estado y

Sociedad (CEDES) CONICET,

Argentina

Juan Carlos González Faraco

Universidad de Huelva, España

María Clemente Linuesa

Universidad de Salamanca, España

Jaume Martínez Bonafé

Universitat de València, España
Miriam Rodríguez Vargas

Universidad Autónoma de

Tamaulipas, México

José Gregorio Rodríguez

Universidad Nacional de Colombia, Colombia

Mario Rueda Beltrán Instituto de

Investigaciones sobre la

Universidad y la Educación,

UNAM, México

José Luis San Fabián Maroto

Universidad de Oviedo,

España

Jurjo Torres Santomé,

Universidad de la Coruña, España

Instituto de Investigaciones sobre

la Universidad y la Educación,

UNAM, México

María Guadalupe Olivier Tellez, Universidad Pedagógica Nacional, México

Miguel Pereyra Universidad de

Granada, España

Mónica Pini Universidad Nacional de San Martín, Argentina

Omar Orlando Pulido Chaves Instituto para la Investigación Educativa y el Desarrollo Pedagógico (IDEP)

José Ignacio Rivas Flores Universidad de Málaga, España
Yengny Marisol Silva Laya Universidad Iberoamericana, México

Ernesto Treviño Ronzón Universidad Veracruzana, México
Ernesto Treviño Villarreal Universidad Diego Portales Santiago, Chile Antoni Verger Planells Universidad Autónoma de Barcelona, España

Catalina Wainerman Universidad de San Andrés, Argentina Juan Carlos Yáñez Velazco Universidad de Colima, México 


\section{education policy analysis archives editorial board}

Lead Editor: Audrey Amrein-Beardsley (Arizona State University)

Editor Consultor: Gustavo E. Fischman (Arizona State University)

Associate Editors: Melanie Bertrand, David Carlson, Lauren Harris, Danah Henriksen, Eugene Judson, Mirka Koro-Ljungberg, Daniel Liou, Scott Marley, Molly Ott, Iveta Silova (Arizona State University)

Madelaine Adelman Arizona State University

Cristina Alfaro

San Diego State University

Gary Anderson

New York University

Michael W. Apple

University of Wisconsin, Madison

Jeff Bale University of Toronto,

Canada

Aaron Benavot SUNY Albany

David C. Berliner

Arizona State University

Henry Braun Boston College

Casey Cobb

University of Connecticut

Arnold Danzig

San Jose State University

Linda Darling-Hammond

Stanford University

Elizabeth H. DeBray

University of Georgia

David E. DeMatthews

University of Texas at Austin

Chad d'Entremont Rennie Center

for Education Research \& Policy

John Diamond

University of Wisconsin, Madison

Matthew Di Carlo

Albert Shanker Institute

Sherman Dorn

Arizona State University

Michael J. Dumas

University of California, Berkeley

Kathy Escamilla

University of Colorado, Boulder

Yariv Feniger Ben-Gurion

University of the Negev

Melissa Lynn Freeman

Adams State College

Rachael Gabriel

University of Connecticut
Amy Garrett Dikkers University

of North Carolina, Wilmington

Gene V Glass

Arizona State University

Ronald Glass University of

California, Santa Cruz

Jacob P. K. Gross

University of Louisville

Eric M. Haas WestEd

Julian Vasquez Heilig California

State University, Sacramento

Kimberly Kappler Hewitt

University of North Carolina

Greensboro

Aimee Howley Ohio University

Steve Klees University of Maryland

Jaekyung Lee SUNY Buffalo

Jessica Nina Lester

Indiana University

Amanda E. Lewis University of

Illinois, Chicago

Chad R. Lochmiller Indiana

University

Christopher Lubienski Indiana

University

Sarah Lubienski Indiana

University

William J. Mathis

University of Colorado, Boulder

Michele S. Moses

University of Colorado, Boulder

Julianne Moss

Deakin University, Australia

Sharon Nichols

University of Texas, San Antonio

Eric Parsons

University of Missouri-Columbia

Amanda U. Potterton

University of Kentucky

Susan L. Robertson

Bristol University
Gloria M. Rodriguez

University of California, Davis

R. Anthony Rolle

University of Houston

A. G. Rud

Washington State University

Patricia Sánchez University of

Texas, San Antonio

Janelle Scott University of

California, Berkeley

Jack Schneider University of

Massachusetts Lowell

Noah Sobe Loyola University

Nelly P. Stromquist

University of Maryland

Benjamin Superfine

University of Illinois, Chicago

Adai Tefera

Virginia Commonwealth University

A. Chris Torres

Michigan State University

Tina Trujillo

University of California, Berkeley

Federico R. Waitoller

University of Illinois, Chicago

Larisa Warhol

University of Connecticut

John Weathers University of

Colorado, Colorado Springs

Kevin Welner

University of Colorado, Boulder

Terrence G. Wiley

Center for Applied Linguistics

John Willinsky

Stanford University

Jennifer R. Wolgemuth

University of South Florida

Kyo Yamashiro

Claremont Graduate University

Miri Yemini

Tel Aviv University, Israel 